\title{
Application of Fourier Transform Infrared Spectroscopy for Monitoring Short-Chain Free Fatty Acids in Swiss Cheese
}

\author{
N. Koca, ${ }^{\star} \dagger$ L. E. Rodriguez-Saona, ${ }^{*}$ W. J. Harper, ${ }^{*}$ and V. B. Alvarez ${ }^{\star 1}$ \\ *Department of Food Science and Technology, The Ohio State University, 110 Parker Food Science and Technology Building, \\ 2015 Fyffe Rd., Columbus 43210 \\ †Department of Food Engineering, Ege University, 35100 Bornova, Izmir, Turkey
}

\section{ABSTRACT}

Short-chain free fatty acids (FFA) are important sources of cheese flavor and have been reported to be indicators for assessing quality. The objective of this research was to develop a simple and rapid screening tool for monitoring the short-chain FFA contents in Swiss cheese by using Fourier transform infrared spectroscopy (FTIR). Forty-four Swiss cheese samples were evaluated by using a MIRacle three-reflection diamond attenuated total reflectance (ATR) accessory. Two different sampling techniques were used for FTIR/ATR measurement: direct measurement of Swiss cheese slices $(\sim 0.5 \mathrm{~g})$ and measurement of a water-soluble fraction of cheese. The amounts of FFA (propionic, acetic, and butyric acids) in the water-soluble fraction of samples were analyzed by gas chromatography-flame ionization detection as a reference method. Calibration models for both direct measurement and the watersoluble fraction of cheese were developed based on a cross-validated (leave-one-out approach) partial least squares regression by using the regions of 3,000 to $2,800,1,775$ to 1,680 , and 1,500 to $900 \mathrm{~cm}^{-1}$ for shortchain FFA in cheese. Promising performance statistics were obtained for the calibration models of both direct measurement and the water-soluble fraction, with improved performance statistics obtained from the watersoluble extract, particularly for propionic acid. Partial least squares models generated from FTIR/ATR spectra by direct measurement of cheeses gave standard errors of cross-validation of $9.7 \mathrm{mg} / 100 \mathrm{~g}$ of cheese for propionic acid, $9.3 \mathrm{mg} / 100 \mathrm{~g}$ of cheese for acetic acid, and 5.5 $\mathrm{mg} / 100 \mathrm{~g}$ of cheese for butyric acid, and correlation coefficients $>0.9$. Standard error of cross-validation values for the water-soluble fraction were $4.4 \mathrm{mg} / 100 \mathrm{~g}$ of cheese for propionic acid, $9.2 \mathrm{mg} / 100 \mathrm{~g}$ of cheese for acetic acid, and $5.2 \mathrm{mg} / 100 \mathrm{~g}$ of cheese for butyric acid with correlation coefficients of $0.98,0.95$, and 0.92 , re-

Received January 27, 2007.

Accepted April 26, 2007.

${ }^{1}$ Corresponding author: alvarez.23@osu.edu spectively. Infrared spectroscopy and chemometrics accurately and precisely predicted the short-chain FFA content in Swiss cheeses and in the water-soluble fraction of the cheese.

Key words: Swiss cheese, free fatty acid, infrared spectroscopy, multivariate analysis

\section{INTRODUCTION}

Short-chain FFA are important sources of cheese flavor. Moreover, they contribute to cheese flavor as precursors for the production of other volatile flavor compounds (McSweeney, 2004). These components are also useful parameters for evaluating the quality of some types of cheeses (Innocente et al., 2000). Bosset and Gauch (1993) reported that FFA found even in low concentrations contribute to the flavor of Cheddar, Gouda, and Swiss cheeses when they are in good balance with the products of proteolysis and other reactions. In Swiss cheese production, thermophilic lactic acid bacteria and propionibacteria are used as starters for the development of its characteristic flavor (Langsrud and Reinbold, 1973). Thermophilic bacteria degrade lactose to lactic acid in the first day of production (Thierry et al., 2004), and propionibacteria metabolize the lactic acid to propionic and acetic acids during warm room ripening at 18 to $24^{\circ} \mathrm{C}$. The amounts of propionic and acetic acids and their relative proportions are important for Swiss cheese flavor (Piveteau, 1999).

Determination of FFA in dairy products is somewhat difficult because the FFA are found as $<0.5 \%$ of total fat in a wide range of carbon chain numbers (from 2 to 20 ) in these products, and short-chain FFA (2:0 to 6:0) are extremely volatile (Chavarri et al., 1997). Gas chromatography has commonly been used for the determination of FFA in cheese. Lipid extraction, isolation of FFA, and gas chromatographic quantification of the individual FFA are involved in most published methods (de Jong and Badings, 1990). Recently, there has also been a trend to use GC-MS and liquid chromatographymass spectroscopy (Collins et al., 2003). However, these methods are time-consuming, expensive, and also re- 
quire hazardous chemicals and trained users. According to Lues and Bekker (2002), the possibilities of predicting the quality of cheese during maturation, or of categorizing cheese by means of a few selected variables are prospects that hold many advantages for the cheese maker. Development of a simple, nondestructive, and rapid method for direct determination of FFA will save the cheese maker time and money while standardizing the quality of the final product.

Infrared spectroscopy is an attractive technology for rapid, inexpensive, sensitive, and high-throughput analysis of food components and does not require special skills by the users. Advances in Fourier transform infrared (FTIR) instrumentation and pattern-recognition techniques have made it possible to extract information from the spectra related to the composition and conformation of food components. Developments in multivariate techniques for classification and regression have been prompted by the need for reliable, accurate, robust, and simple methods for routine analysis of spectroscopic data in agriculture, microbiology, medicine, diagnostics, and other fields (Udelhoven et al., 2000). Mid-infrared spectroscopy $\left(4,000\right.$ to $\left.700 \mathrm{~cm}^{-1}\right)$ allows for chemically based discrimination of organic constituents, producing distinct and reproducible biochemical fingerprints that arise from group vibrations with known assignments in most cases.

Few reports have evaluated the application of midinfrared spectroscopy for cheese analysis because of difficulties in the sampling procedures due to heterogeneity of the components in the cheese (McQueen et al., 1995). Mid-infrared spectroscopy has mainly been used for monitoring the geographic origin of a variety of cheeses (Picque et al., 2002; Pillonel et al., 2003) and for determining the major components (protein, fat, moisture) in cheese (McQueen et al., 1995; Chen et al., 1998; Rodriguez-Saona et al., 2006). There has been one attempt to determine VFA in cheese by using Fourier transform near-infrared reflectance spectroscopy, with encouraging results reported for acetic acid $(r=0.93)$, but not for propionic and butyric acids, with correlation coefficients $<0.81$ (Sgorlon et al., 2003).

The objective of this research was to develop a simple and rapid screening tool for monitoring the short-chain FFA (acetic, propionic, and butyric acids) contents in Swiss cheese by FTIR/attenuated total reflectance (ATR) spectroscopy.

\section{MATERIALS AND METHODS}

\section{Cheese Samples}

Forty-four commercial Swiss cheese samples ( 500 g), supplied by different Swiss cheese manufacturers in Ohio, were taken on different production dates and at different aging times, ranging from just after production to more than $120 \mathrm{~d}$. Cheese samples were vacuumpackaged, stored under refrigerated $\left(4\right.$ to $\left.7^{\circ} \mathrm{C}\right)$ conditions, and analyzed within $2 \mathrm{wk}$.

\section{Reference Analyses of Water-Soluble FFA}

Water-soluble FFA in cheese were extracted by modification of the methods reported by Kuchroo and Fox (1982) and Kleinhenz and Harper (1997). Cheese samples were grated immediately after FTIR measurement, kept in vacuum bags in the refrigerator, and analyzed within $2 \mathrm{~d}$. The grated cheese was crushed in a mortar. A water extract was prepared in a Stomacher bag (STO400, Tekmar Co., Cincinnati, OH) with $10 \mathrm{~g}$ of cheese, $18.5 \mathrm{~mL}$ of deionized water, and $1.5 \mathrm{~mL}$ of internal standard containing $20 \mathrm{mg} / \mathrm{mL}$ of 3-methyl acetic acid (Sigma-Aldrich Co., St. Louis, MO). After homogenizing the samples with a Stomacher for 10 min and holding them in a water bath at $40^{\circ} \mathrm{C}$ for $1 \mathrm{~h}$, the mixture was centrifuged (Sorvall SS34, Kendro Lab Products, Newtown, CT) in 50-mL polypropylene screw-capped centrifuge bottles at $8^{\circ} \mathrm{C}$ and $10,000 \times g$ for $30 \mathrm{~min}$. The samples were then kept in ice for $30 \mathrm{~min}$ and filtered through glass wool by breaking the solid fat layer. The $\mathrm{pH}$ of the supernatant was adjusted to 4.0 with $85 \%$ concentrated phosphoric acid (Mallinckrodt Inc., St. Louis, MO) at $25^{\circ} \mathrm{C}$ to precipitate $\mathrm{CN}$. The acidified supernatant was kept at $-18^{\circ} \mathrm{C}$ overnight to aggregate the protein. The supernatant was centrifuged at 12,000 $\times g$ and $4^{\circ} \mathrm{C}$ for 30 min to remove the protein residue and was then filtered through $0.2-\mu \mathrm{m}$ filters (Fisherbrand 25-mm syringe filters, polytetrafluoroethylene membrane, $0.45-\mu \mathrm{m}$ pore size, Fisher Scientific, Pittsburgh, PA). Water extracts were kept in the refrigerator and analyzed within $2 \mathrm{~d}$ by FTIR spectroscopy. A gas chromatograph (HP 6890, Agilent Technologies Inc., Wilmington, DE) equipped with a flame-ionization detector and a $25 \mathrm{~m} \times 0.32 \mathrm{~mm}$ capillary column (HPFFAP, J\&W Scientific columns from Agilent Technologies) with a $0.5-\mu \mathrm{m}$ film thickness was used for the quantitative analysis of volatile FFA in Swiss cheese. A volume of $0.5 \mu \mathrm{L}$ of water extract was injected manually (SGE Syringe Perfection, 23-gauge microvolume syringe, Restek Corp., Bellefonte, PA). The injection port and flame-ionization detector temperatures were 220 and $270^{\circ} \mathrm{C}$, respectively. The oven temperature was held at $110^{\circ} \mathrm{C}$ for $1 \mathrm{~min}$ and increased by $10^{\circ} \mathrm{C}$ per minute to $230^{\circ} \mathrm{C}$. A post run at $238^{\circ} \mathrm{C}$ was applied for $10 \mathrm{~min}$. The split injection mode was used, with a split ratio of 1:1. The velocity of carrier gas (pure helium) was $44.8 \mathrm{~cm} / \mathrm{s}$. Agilent Chemstation data analysis software (Agilent Technologies, Wilmington, DE) was used for integrating the chromatograms, and a multiple-point 
internal standard method was used for quantifying acetic, propionic and butyric acids. Pure fatty acid standards (Sigma-Aldrich Co.) at different levels were used to generate a calibration curve. The amounts of FFA were calculated as milligrams in $100 \mathrm{~g}$ of cheese. Two replicates were analyzed for each cheese.

\section{FTIR/ATR Spectroscopy Measurements}

Infrared spectra were recorded between 4,000 and $700 \mathrm{~cm}^{-1}$ at a resolution of $4 \mathrm{~cm}^{-1}$ on a FTS Excalibur 3500GX FTIR spectrometer (Digilab, Randolph, MA) mounted with a MIRacle ATR accessory equipped with a high-pressure clamp (Pike Technologies, Madison, WI). The instrument had a computer-controlled dualsource assembly with a Permaglow mid-infrared source and extended-range $\mathrm{KBr}$ beam splitter. Additionally, a 3-reflection diamond ATR crystal provided an increase in sample absorbance, allowing measurement of low concentrations of components (Pike Technologies, 2004).

Two different sampling techniques were used for FTIR measurements: direct measurement of cheese slices and use of the water-soluble fraction of cheese. For direct measurement, cheese slices (about $0.5 \mathrm{~g}$ ) were taken from different areas of the Swiss cheese sample, avoiding the eyes. The samples were pressed with the high-pressure clamp to ensure a good contact between the sample and the diamond crystal. For measurement of the water-soluble fraction, $10 \mu \mathrm{L}$ of the water extract used for the gas chromatography experiments was placed onto the diamond ATR crystal and the water was evaporated under vacuum to obtain a thin, dry film. To improve the signal-to-noise ratio, 128 scans were co-added for each spectrum. The absorbance spectrum was obtained by rationing the single-beam spectrum against that of the air background. Four spectra, each obtained from independent pieces of cheese samples, were recorded for direct measurements, and 2 spectra, each obtained from the water-soluble fractions, were collected for the water-soluble FFA measurements. Each sample was removed from the ATR and replaced with a new one before spectral collection. Pure fatty acids in liquid form (Sigma-Aldrich Co.) were placed individually onto the diamond ATR crystal as a thin film to obtain each fatty acid spectrum.

\section{Multivariate Data Analysis}

Partial least squares regression was applied to generate calibration models with Pirouette pattern-recognition software (Version 3.02 for Windows NT, Infometrix, Inc., Woodinville, WA). The optimum number of latent variables used for prediction was determined by full cross-validation (a leave-one-out approach). The performance of the resulting models was evaluated in terms of the standard error of calibration, standard error of cross-validation (SECV), and coefficient correlations ( $\mathrm{r}$ ) for the calibration and validation models. The model producing the first local minimum SECV was selected as the best model for the spectral data set (Haaland and Thomas, 1988; Martens and Naes, 1989).

\section{RESULTS AND DISCUSSION}

\section{Characterization of FTIR Spectra of Pure FFA}

The pure FFA (2:0 to 6:0) acetic, propionic, butyric, and $n$-caproic acids were analyzed by FTIR/ATR to obtain spectral information for each fatty acid, with the spectral bands arising from specific functional group vibrations. The spectra of pure fatty acids had strong absorptions between 3,000 and $2,800 \mathrm{~cm}^{-1}, \sim 1,680$ and $1,775 \mathrm{~cm}^{-1}$, and also in the fingerprint region of 1,500 and $700 \mathrm{~cm}^{-1}$ (Figure 1).

Each fatty acid gave different mid-infrared band intensities that could be used to develop prediction models by multivariate analysis to determine the FFA contents. The absorptions observed in the region of 3,000 to $2,800 \mathrm{~cm}^{-1}$ corresponded to the asymmetric $\mathrm{C}-\mathrm{H}$ stretching of methyl and methylene groups $(2,900$ to $2,800 \mathrm{~cm}^{-1}$ ) and symmetric C-H stretching of methyl and methylene groups $\left(2,900\right.$ to $2,800 \mathrm{~cm}^{-1}$; Karoui et al., 2005). Increases in carbon chains and molecular weights of FFA resulted in higher relative intensities of $\mathrm{C}-\mathrm{H}$ stretching groups, which were most obvious in the symmetric C-H stretching region. Coates (2000) reported that a characteristic broad band in the 3,300 to $2,500 \mathrm{~cm}^{-1}$ region, corresponding to the hydrogenbonded $\mathrm{O}-\mathrm{H}$ of most carboxylic acids, overlaps the $\mathrm{C}-\mathrm{H}$ stretching region. In Figure 1, this broad band is clearly seen for all fatty acids.

All pure fatty acids showed a strong band at $\sim 1,710$ $\mathrm{cm}^{-1}$, corresponding to absorption by carbonyl double bonds $(\mathrm{C}=\mathrm{O}$ stretching) in FFA. Carboxylic acid can easily be distinguished from all other carbonyl compounds, with a broad band at 1,700 to $1,725 \mathrm{~cm}^{-1}$. Common bands for all short-chain fatty acids in the fingerprint region were observed at $\sim 1,415, \sim 1,240$, and $\sim 935$ $\mathrm{cm}^{-1}$, corresponding to C-O-H in-plane bending, C-O stretching, and $\mathrm{O}-\mathrm{H}$ out-of-plane bending, respectively.

\section{Characterization of FTIR Spectra of Cheese Samples}

Two approaches (direct measurement and with the water-soluble fraction) were used for sampling to determine the FFA in Swiss cheese with FTIR/ATR. The Savitzky-Golay second-derivative transform (Figures 2 


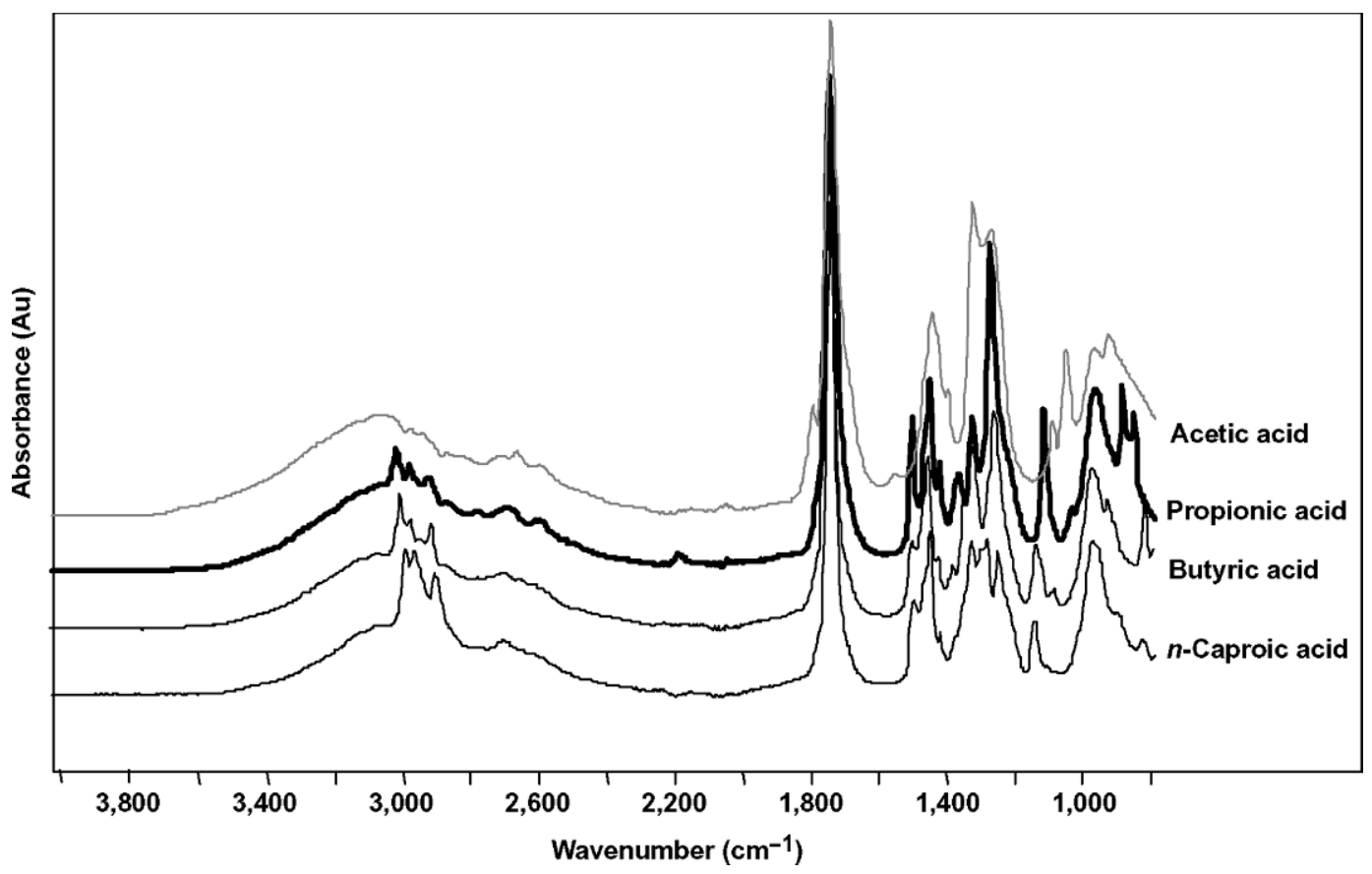

Figure 1. Mid-infrared spectra of standard short-chain fatty acids (2:0 to 6:0) in the 4,000 to $700 \mathrm{~cm}^{-1}$ region. AU $=$ arbitrary units.

and 3) allowed the extraction of useful band information through the removal of baseline variations and resolution of overlapping peaks (Hrushka, 1987). The information-rich infrared spectral ranges for direct measurement of Swiss cheese samples were 3,000 to 2,800 $\mathrm{cm}^{-1}$ and 1,800 to $900 \mathrm{~cm}^{-1}$, with strong and well-separated bands (Figure 2). The direct measurement spec- trum shows the spectral bands arising from amides I and II $\left(1,650\right.$ to $1,540 \mathrm{~cm}^{-1}$ ), lipids (3,000 to 2,800 $\mathrm{cm}^{-1}$ and 1,800 to $1,700 \mathrm{~cm}^{-1}$ ), and water (3,700 to 2,500 $\mathrm{cm}^{-1}$ and 1,700 to $1,600 \mathrm{~cm}^{-1}$ ), which were detailed by Rodriguez-Saona et al. (2006). The spectrum had strong bands at 2,920 and $2,850 \mathrm{~cm}^{-1}$ (C-H stretching of methylene groups), $1,745 \mathrm{~cm}^{-1}$ (carbonyl groups), 1,460 (C-

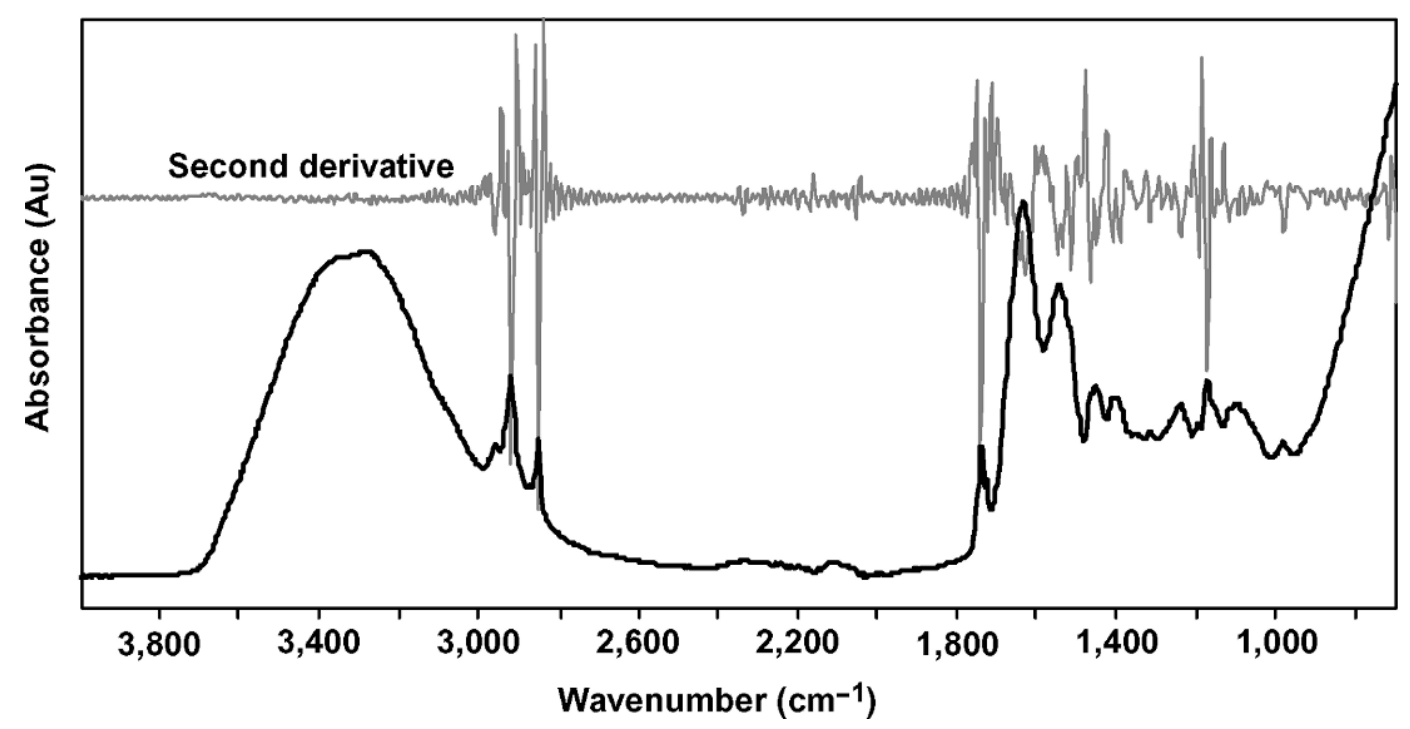

Figure 2. Mid-infrared spectra and second-derivative spectral transformation of Swiss cheese using Fourier transform infrared spectroscopy-attenuated total reflectance spectroscopy. AU = arbitrary units. 


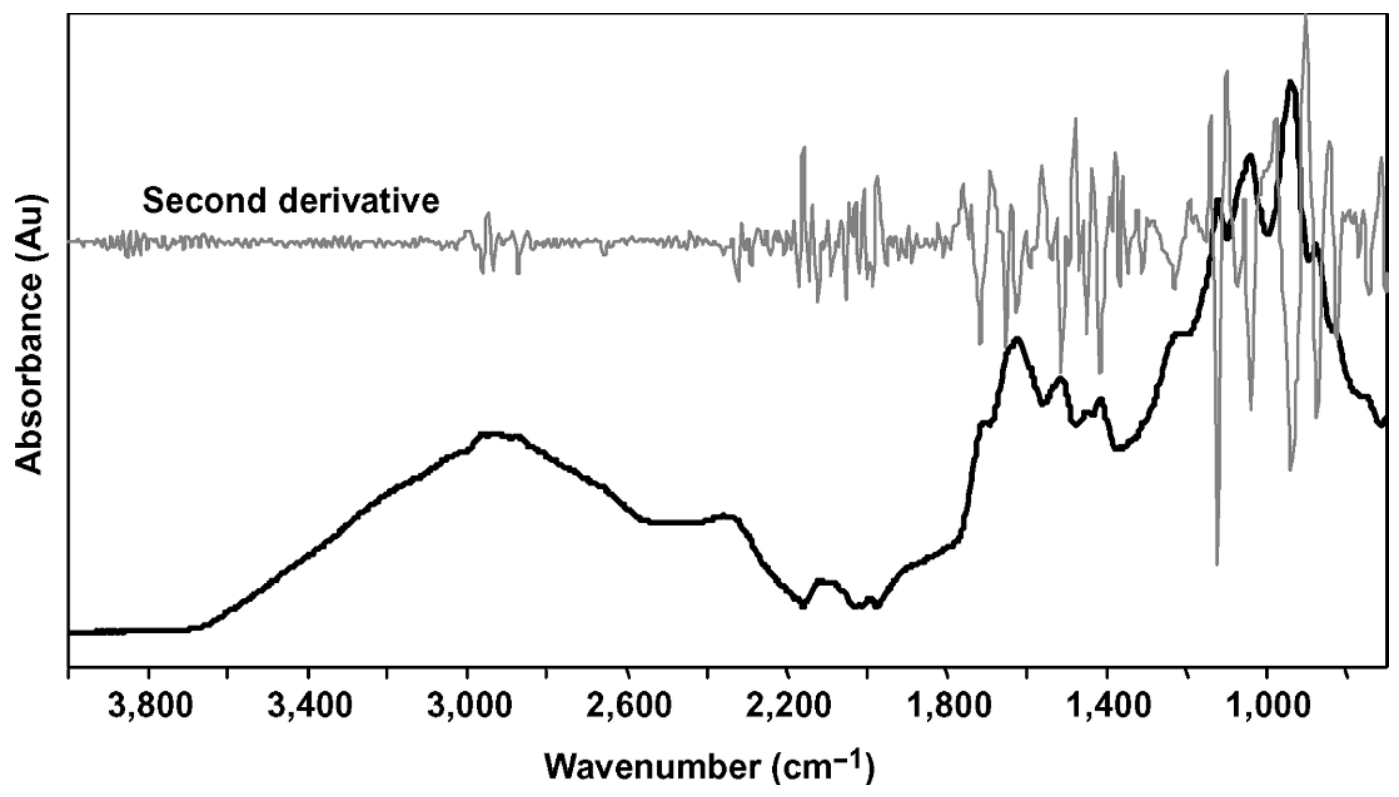

Figure 3. Mid-infrared spectra and second-derivative spectral transformation of the water-soluble fraction of Swiss cheese by Fourier transform infrared spectroscopy-attenuated total reflectance spectroscopy. AU = arbitrary units.

$\mathrm{H}$ bending), and $1,175 \mathrm{~cm}^{-1}$ (C-O stretching) for direct cheese measurement. The spectrum also exhibited fatrelated bands at 1,477 to $1,400 \mathrm{~cm}^{-1}$ (C-H bending), $1,240 \mathrm{~cm}^{-1}$, and 1,170 to 1,115 (C-O stretching; Chen et al., 1998).

Although the direct measurement protocol was very simple, the high amount of fat and protein in cheese resulted in interferences. Therefore, in the second approach, the water extract of cheese samples was used to remove fat and protein while retaining the watersoluble acetic, propionic, and butyric acids to attempt to improve the ability of the multivariate analysis to detect the FFA (Figure 3). The water-soluble fraction of cheese contains volatile polar compounds consisting mainly of short- and medium-chain-length FFA (Engel et al., 2002) and nonvolatile compounds, such as mineral salts, lactic acid, lactose, AA, and peptides (Aston and Creamer, 1986). As seen in the second-derivative spectrum of the water-soluble fraction of cheeses (Figure 3), less intense bands, as compared with the direct measurements, were obtained between 3,000 and 2,800 $\mathrm{cm}^{-1}$ and 1,775 and $1,600 \mathrm{~cm}^{-1}$ because of the removal of fat and proteins during the extraction procedure with water. A strong band at $\sim 1,710 \mathrm{~cm}^{-1}$ was obtained in the water-soluble fraction spectrum, corresponding to absorption by carbonyl bonds $(\mathrm{C}=\mathrm{O}$ stretching) of carboxylic acids and a small band at $1,750 \mathrm{~cm}^{-1}$ arising from carbonyl groups of esters. One of the most visible differences between the spectra from direct measurement and from the water-soluble fraction was the

Table 1. Calibration and cross-validation results of FFA analysis by FTIR/ATR spectroscopy ${ }^{1}$

\begin{tabular}{lcccccccc}
\hline $\begin{array}{l}\text { Range of FFA } \\
\text { (mg/100 g of cheese) }\end{array}$ & Technique $^{2}$ & $\begin{array}{c}\text { Number } \\
\text { of samples }\end{array}$ & $\begin{array}{c}\text { Latent } \\
\text { variables }\end{array}$ & $\begin{array}{c}\text { Cumulative } \\
\text { variance }\end{array}$ & SEC & rCal & SECV & rVal \\
\hline Acetic acid (20-160) & DM & 44 & 9 & 90.7 & 5.92 & 0.98 & 9.28 & 0.95 \\
& WSF & 44 & 10 & 85.8 & 2.71 & 0.99 & 9.16 & 0.95 \\
Propionic acid (0-100) & DM & 42 & 10 & 92.9 & 5.60 & 0.97 & 9.69 & 0.91 \\
& WSF & 42 & 10 & 84.9 & 0.97 & 0.99 & 4.36 & 0.98 \\
Butyric acid (0-50) & DM & 39 & 11 & 94.0 & 2.27 & 0.99 & 5.51 & 0.92 \\
& WSF & 39 & 9 & 86.5 & 1.31 & 0.99 & 5.24 & 0.92 \\
\hline
\end{tabular}

\footnotetext{
${ }^{1}$ Mid-infrared analysis was performed using the 3,000 to $2,800,1,775$ to 1,680 , and 1,500 to $900 \mathrm{~cm}^{-1}$ regions. SEC = standard error of calibration; $\mathrm{SECV}=$ standard error of validation; rCal = correlation coefficient of calibration; $\mathrm{rVal}=$ correlation coefficient of cross-validation; latent variables = small number of orthogonal factors providing the optimal linear model in terms of predictability; cumulative variance $=$ measure of the percentage of variance explained by the model.

${ }^{2} \mathrm{DM}=$ direct measurement of Swiss cheese samples; $\mathrm{WSF}=$ water-soluble fraction of Swiss cheese samples.
} 

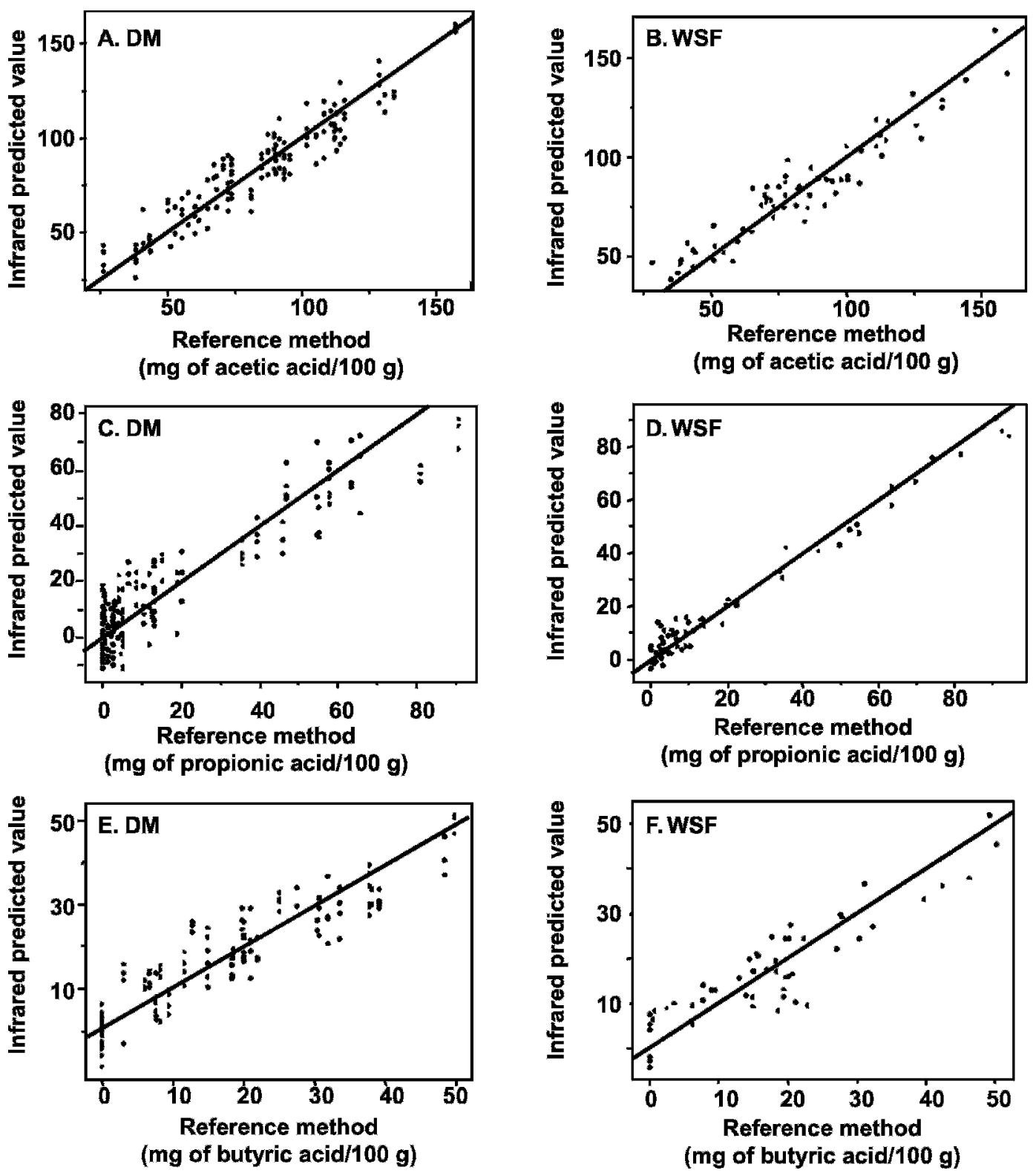

Figure 4. Partial least squares regression cross-validation plots for acetic, propionic, and butyric acids in Swiss cheese samples for direct measurements (DM; A, C, E) and for the water-soluble fraction (WSF; B, D, F).

stronger and well-separated bands in the 1,500 to 800 $\mathrm{cm}^{-1}$ region of the water-soluble fraction. Irudayaraj and Tewari (2003) assigned the bands in the region 1,153 to $904 \mathrm{~cm}^{-1}$ to $\mathrm{C}-\mathrm{O}$ and $\mathrm{C}-\mathrm{C}$ stretching modes and those in the region 1,474 to $1,199 \mathrm{~cm}^{-1}$ to $\mathrm{O}-\mathrm{C}-\mathrm{H}, \mathrm{C}-\mathrm{C}-$ $\mathrm{H}$, and $\mathrm{C}-\mathrm{O}-\mathrm{H}$ vibrational modes arising from sugars and organic acids.

\section{Comparison of the Sampling Techniques}

The regions 3,000 to $2,800,1,775$ to 1,680 , and 1,500 to $900 \mathrm{~cm}^{-1}$ were used to develop calibration models for acetic, propionic, and butyric acids, with the levels given in Table 1. The cross-validated (leave-one-out) partial least squares regression results for direct measurement and for the water-soluble fraction are shown in Table 1 and Figure 4. Direct measurement of cheese showed good performance statistics, with estimated SECV of $9.28,9.68$, and $5.51 \mathrm{mg} / 100 \mathrm{~g}$ of cheese for acetic, propionic, and butyric acids, respectively, and correlation coefficients of $>0.91$. On the other hand, the water-soluble fraction gave higher correlation coefficients of validation $(>0.92)$ and lower SECV values $(9.16,4.36$, and $5.24 \mathrm{mg} / 100 \mathrm{~g}$ of cheese for acetic, propi- 
onic, and butyric acids, respectively) compared with direct measurement. The superiority of using the water-soluble fraction over direct measurement was more visible for propionic acid than for the other fatty acids, with SECV of $4.36 \mathrm{mg} / 100 \mathrm{~g}$ for the water-soluble fraction, which can be clearly seen in Figure 4D. This could be attributed to the combination of different limitations of the direct measurement technique for the cheese. Cheeses are heterogeneous, showing differences in composition in different parts of the same sample (McQueen et al., 1995; Rodriguez-Saona et al., 2006). Additionally, Swiss cheese contains eyes that introduce further interfering variability into the infrared spectral data. In fact, Kleinhenz (1995) reported that the amounts of acetic, propionic, and butyric acids in the areas closer to eye sections were significantly different from those in the middle section of Swiss cheese. Other sources of variability include morphological changes during aging (McQueen et al., 1995), heterogeneity of fat globules, bound moisture in the protein matrix, and the presence of voids in the cheese matrix (Chen and Irudayaraj, 1998). Advantages of using the water-soluble fraction included analysis of a homogeneous sample for the extraction of FFA with water and limited interference of fat (medium- and long-chain fatty acids) and protein. Therefore, short-chain fatty acids became more dominant in the water-soluble fraction. In this research, lower SECV values and higher correlation coefficient values were obtained than those in Montasio cheese studied by Fourier transform near-infrared spectroscopy with reported correlation coefficient values of 0.93 , 0.80 , and 0.81 for acetic, propionic, and butyric acids, respectively (Sgorlon et al., 2003.)

A major advantage of measuring the cheese directly by applying infrared spectroscopy was the ability to rapidly obtain a spectrum that contained information about its physicochemical characteristics. Although the direct measurement technique gave slightly higher SECV values than the water-soluble fraction, this rapid measurement technique could be valuable for routine quality control and online analysis of FFA for the cheese industry.

\section{CONCLUSIONS}

A simple and rapid FTIR/ATR method was developed for the determination of short-chain FFA in Swiss cheese. Overall, good performance statistics were obtained by direct measurement and by using water-soluble extracts. In particular, the water-soluble fraction of the cheese allowed the confounding signal to be minimized and improved the performance of the prediction models with SECV of $4.4 \mathrm{mg}$ of propionic acid/100 $\mathrm{g}$ of cheese detected and a correlation coefficient of 0.98 .
The potential of FTIR/ATR spectroscopy for simple, rapid ( $<3 \mathrm{~min}$ ), and accurate determination of the major and minor constituents in Swiss cheese was shown. Developing simple extraction protocols can improve the capabilities of the infrared technique for qualitative and quantitative analysis of cheese.

\section{REFERENCES}

Aston, J., and L. K. Creamer. 1986. Contribution of the components of water-soluble fraction to the flavor of Cheddar cheese. N. Z. Dairy Sci. Technol. 21:229-248.

Bosset, J. O., and R. Gauch. 1993. Comparison of the volatile flavor compounds of six European 'AOC' cheeses by using a new dynamic headspace GC-MS method. Int. Dairy J. 3:359-377.

Chavarri, F., M. Virto, C. Martin, A. I. Najera, A. Santisteban, L. J. R. Barron, and de M. Renobales. 1997. Determination of free fatty acids in cheese: Comparison of two analytical methods. J. Dairy Res. 64:445-452.

Chen, M., J. Irudayaraj, and D. J. McMahon. 1998. Examination of full fat and reduced fat Cheddar cheese during ripening by Fourier transform infrared spectroscopy. J. Dairy Sci. 81:2791-2797.

Chen, M., and J. Irudayaraj. 1998. Sampling technique for cheese analysis by FT-IR spectroscopy. J. Food Sci. 63:96-99.

Coates, J. 2000. Interpretation of infrared spectra, a practical approach. Pages 10815-10837 in Encyclopedia of Analytical Chemistry. R. R. Meyers, John Wiley and Sons, Chichester, UK.

Collins, Y. F., P. L. H. McSweeney, and M. G. Wilkinson. 2003. Lipolysis and free fatty acid catabolism in cheese: A review of current knowledge. Int. Dairy J. 13:841-866.

de Jong, C., and H. T. Badings. 1990. Determination of free fatty acids in milk and cheese: Procedures for extraction, clean up and capillary gas chromatographic analysis. J. High Resolut. Chromatogr. 13:94-98.

Engel, E., J. B. Lombardot, A. Garem, N. Leconte, C. Septier, J. L. Le Quere, and C. Salles. 2002. Fractionation of the water-soluble extract of cheese made from goats' milk by filtration methods: Behavior of fat and volatile compounds. Int. Dairy J. 12:609-619.

Haaland, D. M., and E. V. Thomas. 1988. Partial least-squares methods for spectral analyses. 1. Relation to other quantitative calibration methods and the extraction of qualitative information. Anal. Chem. 60:1193-1202.

Hrushka, W. R. 1987. Data analysis: Wavelength selection methods. Pages 35-55 in Near-Infrared Technology in the Agricultural and Food Industries. P. Williams and K. Norris, ed. American Association of Cereal Chemists Inc., St. Paul, MN.

Innocente, N., S. Moret, C. Corradini, and L. S. Conte. 2000. A rapid method for the quantitative determination of short-chain free volatile fatty acids from cheese. J. Agric. Food Chem. 48:33213323.

Irudayaraj, J., and J. Tewari. 2003. Simultaneous monitoring of organic acids and sugars in fresh and processed apple juice by Fourier transform infrared-attenuated total reflection spectroscopy. Appl. Spectrosc. 57:1599-1604.

Karoui, R., E. Dufour, L. Pillonel, E. Schaller, D. Picque, T. Cattenoz, and J.-O. Bosset. 2005. The potential of combined infrared and fluorescence spectroscopies as a method of determination of the geographic origin of Emmental cheeses. Int. Dairy J. 15:287-298.

Kleinhenz, J. P. 1995. Lower moleculer weight fatty acids in full-fat and low-fat commercial Swiss cheese. PhD Thesis. Ohio State University, Columbus.

Kleinhenz, J. P., and W. J. Harper. 1997. Comparison of direct capillary electrophoreses and gas capillary chromatographic methods for the determination of lower molecular weight fatty acids in Swiss cheese. Milchwissenschaft 52:200-204.

Kuchroo, C. N., and P. F. Fox. 1982. Soluble nitrogen in Cheddar cheese: Comparison of extraction procedures. Milchwissenschaft 37:331-335. 
Langsrud, T., and G. W. Reinbold. 1973. Flavor development and microbiology of Swiss cheese: A review. III. Ripening and flavor production. J. Milk Food Technol. 36:593-609.

Lues, J. F. R., and A. C. M. Bekker. 2002. Mathematical expressions for organic acids in early ripening of a Cheddar cheese. J. Food Compos. Anal. 15:11-17.

Martens, H., and T. Naes. 1989. Models for calibration. In Multivariate Calibration. H. Martens and T. Naes, ed. John Wiley and Sons Ltd., Chichester, UK.

McQueen, D. H., R. Wilson, A. Kinnunen, and E. P. Jensen. 1995. Comparison of two infrared spectroscopic methods for cheese analysis. Talanta 42:2007-2015.

McSweeney, P. L. 2004. Biochemistry of cheese ripening. Int. J. Dairy Technol. 57:127-144.

Picque, D., T. Cattenoz, and G. Corrieu. 2002. Discrimination of Emmental cheeses by infrared spectroscopy. Milchwissenschaft 57:202-204.

Pike Technologies. 2004. ATR Theory and Applications. Applications Note 0402. Pike Technologies, Madison, WI.
Pillonel, L., W. Luginbühl, D. Picque, E. Schaller, R. Tabacchi, and J. O. Bosset. 2003. Analytical methods for the determination of the geographic origin of Emmental cheese: Mid- and near-infrared spectroscopy. Eur. Food Res. Technol. 216:174-178.

Piveteau, P. 1999. Metabolism of lactate and sugars by dairy propionibacteria: A review. Lait 79:23-41.

Rodriguez-Saona, L. E., N. Koca, W. J. Harper, and V. B. Alvarez. 2006. Rapid determination of Swiss cheese composition by Fourier transform infrared/attenuated total reflectance spectroscopy. J. Dairy Sci. 89:1407-1412.

Sgorlon, S., P. Susmel, G. Procida, and B. Stefanon. 2003. Prediction of chemical composition, volatile fatty acids and volatile compounds in Montasio cheese by Fourier transformed near-infrared reflectance spectroscopy. Sci. Tecn. Latt. Cas. 54:23-34.

Thierry, A., M. B. Maillard, C. Hervè, R. Richoux, and S. Lortal. 2004. Varied volatile compounds are produced by Propionibacterium freundenreichii in Emmental cheese. Food Chem. 87:439-446.

Udelhoven, T., D. Nauman, and J. Schmitt. 2000. Development of a hierarchical classification system with artificial neural networks and FT-IR spectra for the identification of bacteria. Appl. Spectrosc. 54:1471-1479. 